\title{
Media Use and Physical Activity Behaviour of Adolescent Participants in Obesity Therapy: Impact Analysis of Selected Socio- Demographic Factors
}

\author{
Hagen Wulff Petra Wagner \\ Institute of Exercise and Public Health, University of Leipzig, Leipzig, Germany
}

\author{
Keywords \\ Children and adolescents · Obesity · Physical activity · Media use · Socio-demographic \\ factors
}

\begin{abstract}
Background: To address the challenge of juvenile obesity, effective therapeutic concepts focusing on lifestyle changes are necessary. A relevant aspect is the media use, which is associated with nutrition and physical activity patterns and is influenced by socio-demographic factors. To optimise obesity therapy, the use of media depending on these socio-demographic factors needs to be analysed to adjust the aims, content and methods of interventions as well as to harness the potential of media use in obesity therapy. The question considered in this research is: What media and physical activity patterns show 11- to 17-year-old obesity therapy participants in dependence on socio-demographic factors? Methods: A national multicentre study was conducted in 2015. A questionnaire was used to survey 432 participants' aged $13.75 \pm 1.4$ years. Standardised instruments were used to assess the variables: physical activity, media use and socio-demographic factors. Results: The participants were 1-hour physically active for $3.9 \pm 1.9$ days/week, $14.1 \%$ daily. Televisions, mobile phones and computers were available in all socio-demographic groups and used for $2 \mathrm{~h} /$ day. Socio-demographic differences emerged in the duration of media use (h/day). Girls were found to use mobile phones for longer (2.49 vs. 1.90; $p<0.01$ ) and spend less time on game consoles than boys ( 0.55 vs. $1.65 ; p<0.01)$. Conclusion: Compared to current recommendations, the sample shows reduced physical activity and increased media use, which vary between the groups. Hence, differentiated therapy approaches appear recommendable. Future research needs to evaluate, how media (despite its risks) can facilitate therapy, training and aftercare concepts.

(c) 2018 The Author(s)

Published by S. Karger $\mathrm{GmbH}$, Freiburg
\end{abstract}




\section{Introduction}

Overweight and obesity pose enormous challenges for healthcare systems, particularly because of their high prevalence [1] as well as accompanying and secondary diseases [2]. In addition to causing severe problems in individuals, obesity (pathologically elevated body fat levels compared to total body mass) increases health-economic burdens due to lower productivity caused by the incapacity to work accompanied by reduced earning capacities [3].

To counteract these problems at an early stage, national guideline-based obesity therapy concepts for children and adolescents are available, which strive to achieve long-term lifestyle changes improving weight stabilisation and obesity-related co-morbidity [4]. The emphasis on behaviour and living conditions of those affected is, therefore, of particular importance, in order to reduce health-related risk factors in the long run and improve personal resources [4]. However, considering the effectiveness of the guideline-based therapies, the need for optimisation is obvious [5]. This was also shown in the EvAKuJ study [6], in which only $20 \%$ of the participants achieved an effective reduction of their body mass index standard deviation score (BMI-SDS) due to the fact that long-term lifestyle changes could not be sustained. Moreover, the necessity of long-term lifestyle changes to enhance and ensure therapy outcomes is confirmed by Oude Luttikhuis' Cochrane-Review [7].

Besides healthy nutrition and physical activity, one major and partly neglected healthrelated risk factor is juvenile media use. Even though juvenile media use may be associated with nutrition and physical activity behaviour, it is still rarely considered in therapy guidelines and programmes. However, empirical correlations have been identified between media consumption and an intake of energy-dense foods [8] as well as between physical activity and media use. This can be explained with an inactive lifestyle combined with high media consumption, which may be associated with reduced metabolism and long-term weight gain [9]. Various publications based on the KIGGS German Health Interview and Examination Survey for Children and Adolescents indicate similar links. The results show that the prevalence of overweightamong respondents with high media use ( $>3 \mathrm{~h} /$ day) doubled in comparison to respondents with low media use $(<1 \mathrm{~h} /$ day $)[10,11]$. However, associated causal relations are not yet clarified.

Further potential associations between media use, nutrition, physical activity and the genetics of overweight may also be influenced by socio-demographic variables including gender, age, education and family history $[7,9,11,12]$. The Kiel Obesity Prevention Study (KOPS) [13] revealed links between the above-mentioned moderators and lifestyle factors, which may in turn determine body composition. This underlines the need to distinguish and tailor therapy approaches for heterogeneous groups of juvenile obesity therapy participants in an overall effort to achieve sustainable treatment outcomes. Furthermore, the KOPS study [13] emphasises that general recommendations, such as 'less TV use, more activity, less fat', may not be sufficient to meet the patients' needs.

Hence, to develop more effective therapy approaches, it appears necessary to analyse lifestyle variables as a function of socio-demographic determining factors. In a second step, the findings could be used to define and review specific intervention objectives, content and concepts to improve the effectiveness of therapy approaches. Considering this, the central research question is: 'What media and physical activity patterns show 11- to 17-year-old obesity therapy participants in dependence on socio-demographic factors?' 


\section{Material and Methods}

A national multicentre cross-sectional analysis was carried out among 11- to 17-year-old obesity therapy participants in five regions of Germany (Bavaria, Saxony, Thuringia, Mecklenburg West Pomerania and Schleswig-Holstein) in 2015. Participants completed a written questionnaire when starting therapy. A total of 432 participants were surveyed.

The sample showed the following socio-demographic distribution: $66.0 \%$ of participants, from the entire country, were treated in in-patient obesity centres, while $34.0 \%$ were treated in ambulant centres; $55.8 \%$ of participants were female, and $44.2 \%$ were male. The mean age was $13.75 \pm 1.4$ years ( \pm standard deviation); $59.5 \%$ of the respondents were $11-13$ years old and $40.5 \%$ were $14-17$ years old. Participants attended different types of schools: $36.5 \%$ secondary, $22.1 \%$ high, $24.9 \%$ secondary modern, $6.1 \%$ special needs, $1.6 \%$ primary schools and $0.6 \%$ vocational colleges. However, $21.1 \%$ of the participants could not be assigned to a special type of school, due to missing data. Overall, $68.9 \%$ of the participants stated that both of their parents are employed, $28.6 \%$ stated that only one parent is employed, and $2.6 \%$ state that their parents are unemployed. The family structure varied among participants: $11.4 \%$ of the participants had no sibling, $36.6 \%$ had one sibling, and $30.8 \%$ had two siblings.

The data collection applied standardised instruments to gather data to physical activity and media use behaviour as well as socio-demographic variables. Questions of the KIGGS study [14] with satisfactory reliability and validity was used. The physical activity of a normal week was recorded, including outdoor activities, type, volume and setting of performed activities as well as sport club memberships. Multiple answers were accepted concerning setting and sport club membership. Furthermore, media access and daily media use were analysed.

Descriptive and inferential statistical parameters were charted in tables. For greater clarity, not all socio-demographic sub-groups were included in the analysis. For example, unusual or insufficiently comparable school types were excluded. Consequently, the total percentages of sub-groups may not always add up to $100 \%$. To estimate group effects more accurately, a stratified analysis was conducted to identify variability-reducing confounders and other potential sources of bias. The following strata were generated: gender (female or male), age (14-17 and 11-13 years old) and type of school (secondary modern school (low level of education), secondary school (medium level of education), high school (high level of education)) and work status of the parents (employed or unemployed).

The reference groups (Ref.) are outlined first in the tables in brackets to correlate for correlation analysis between group assignment and the likelihood of increased media use or activity. The results are depicted with odds ratios (OR) with a 95\% confidence interval (95\% CI), calculated with a logistic regression. The analysis difference hypotheses was based on the distribution characteristics according to the results of a Mann-Whitney U-test. Further correlations between media use and activity were examined with the Pearson's correlation analysis. Therefore, indexes for media use and activity were created. The significance level was defined at $5 \%$.

\section{Results}

\section{Physical Activity Behaviour}

Participants reported a mean activity level of at least $1 \mathrm{~h}$ on $3.89 \pm 1.88$ days in a normal week. The highest percentage of respondents (23.4\%) showed an activity level of at least $1 \mathrm{~h}$ on 3 days/week, while $14.1 \%$ reported daily activity of at least $1 \mathrm{~h}$.

Significant differences emerged when comparing gender and age groups (table 1). The group of the boys reported increased activity levels of $4.10 \pm 1.95$ active days/week. 11- to 13 -year-olds $(4.08 \pm 1.91)$ were more active than 14 - to 17 -year-olds $(3.63 \pm 1.80)$. Participants spent $5.17 \pm 2.10$ days a week outdoors. There were no significant differences between the groups.

\section{Physical Activity Setting and Sports Club Membership}

The majority of participants (75.2\%) conducted physical activities with friends, $41.5 \%$ were active by themselves, $34.9 \%$ were active in sports clubs, and $32.3 \%$ were active with 
Wulff and Wagner: Media Use and Physical Activity Behaviour of Adolescent

Participants in Obesity Therapy: Impact Analysis of Selected Socio-Demographic

Factors

Table 1. Indicators and statistics on activity behavior by demographic group membership

\begin{tabular}{|c|c|c|c|c|c|c|c|c|c|c|}
\hline & \multirow[t]{2}{*}{ Total } & \multicolumn{2}{|l|}{ Gender } & \multicolumn{2}{|l|}{ Age, years } & \multicolumn{3}{|c|}{ School type } & \multicolumn{2}{|c|}{$\begin{array}{l}\text { Parents' } \\
\text { employment status }\end{array}$} \\
\hline & & female & male & $14-17$ & $11-13$ & $\begin{array}{l}\text { high } \\
\text { school }\end{array}$ & $\begin{array}{l}\text { secondary } \\
\text { school }\end{array}$ & $\begin{array}{l}\text { secondary } \\
\text { modern } \\
\text { school }\end{array}$ & both & neither \\
\hline \multicolumn{11}{|c|}{ Number of days per normal week with at least 60 min of physical exercise } \\
\hline $\mathrm{N}$ (valid/total) & $389 / 432$ & $216 / 241$ & $173 / 191$ & $163 / 175$ & $226 / 257$ & $80 / 87$ & $132 / 144$ & $85 / 98$ & $262 / 294$ & $10 / 11$ \\
\hline MW & 3.89 & 3.72 & 4.10 & 3.63 & 4.08 & 3.96 & 3.71 & 4.04 & 3.92 & 3.90 \\
\hline SD & 1.88 & 1.80 & 1.95 & 1.80 & 1.91 & 1.95 & 1.75 & 1.94 & 1.89 & 1.29 \\
\hline MD & 4.00 & 3.00 & 4.00 & 3.00 & 4.00 & 4.00 & 3.00 & 4.00 & 4,00 & 3.50 \\
\hline IQA & 2.00 & 3.00 & 3.00 & 3.00 & 3.00 & 4.00 & 3.00 & 2.00 & 2.00 & 2.00 \\
\hline $\mathrm{Z}$ & & -1.986 & & -2.265 & & & -0.913 & -0.330 & -0.056 & \\
\hline $\mathrm{P}$ & & $0.047^{*}$ & & $0.024^{*}$ & & & 0.361 & 0.741 & 0.955 & \\
\hline \multicolumn{11}{|c|}{ Number of days per normal week with at least $60 \mathrm{~min}$ of physical exercise outdoors } \\
\hline $\mathrm{N}$ (valid/total) & $403 / 432$ & $225 / 241$ & $178 / 191$ & $162 / 175$ & $241 / 257$ & $82 / 87$ & $137 / 144$ & $85 / 98$ & $269 / 294$ & $11 / 11$ \\
\hline MW & 5.17 & 5.03 & 5.35 & 5.16 & 5.18 & 5.01 & 5.01 & 5.40 & 5.29 & 6.00 \\
\hline SD & 2.10 & 2.19 & 1.98 & 2.09 & 2.12 & 2.11 & 2.09 & 1.97 & 2.14 & 1.55 \\
\hline MD & 5.00 & 5.00 & 5.00 & 5.00 & 5.00 & 5.00 & 5.00 & 5.00 & 5.00 & 6.00 \\
\hline IQA & 4.00 & 4.00 & 4.00 & 4.00 & 4.00 & 3.00 & 4.00 & 4.00 & 4.00 & 3.00 \\
\hline $\mathrm{Z}$ & & -1.454 & & -0.134 & & & -0.264 & -0.825 & -1.125 & \\
\hline$P$ & & 0.146 & & 0.894 & & & 0.792 & 0.409 & 0.260 & \\
\hline
\end{tabular}

their families. Activity in family and friendship settings were similar across socio-demographic groups. The results show that $46.0 \%$ of the 14 - to 17 -year-olds and $50.0 \%$ of the girls preferred to perform activities by themselves without family members, friends or sports club groups. Compared to the reference group, boys were less likely to be active within the family setting (OR 0.45 (0.30-0.67)).

Girls (30.5\%) appeared to be less active in sports clubs than boys (40.4\%). The likelihood of boys (OR 1.55 (1.03-2.31)) participating in sports clubs was 55\% higher than that of girls. Children aged 11-13 years (37.2\%) were more active in sports clubs than adolescents aged 14-17 years (31.6\%). Pupils from secondary modern schools (31.9\%) were less active in sports clubs than high-school students (39.1\%). Participants were holding memberships in different types of sports clubs: $17.2 \%$ dancing, $15.8 \%$ martial arts, $14.0 \%$ football, $7.7 \%$ swimming, $6.7 \%$ handball, $4.9 \%$ table-tennis, $3.9 \%$ health sports and less than $2 \%$ in other sports.

In addition to activities in sports clubs, participants conducted regularly leisure activities such as cycling, football, dancing and swimming. The majority of participants (69.3\%) cycled at least once a week. Socio-demographic differences were not observed in this regard. However, the results show that only a relatively small number of 14- to 17-year-olds were going to swim. Boys were more likely to play football than girls, who preferred to go dancing.

\section{Media Ownership and Access of Technical Devices}

Media access comprises the availability of media at home and the ownership of technical devices (table 2). In $99.5 \%$ of the households, a TV was available; $79.3 \%$ of the participants 


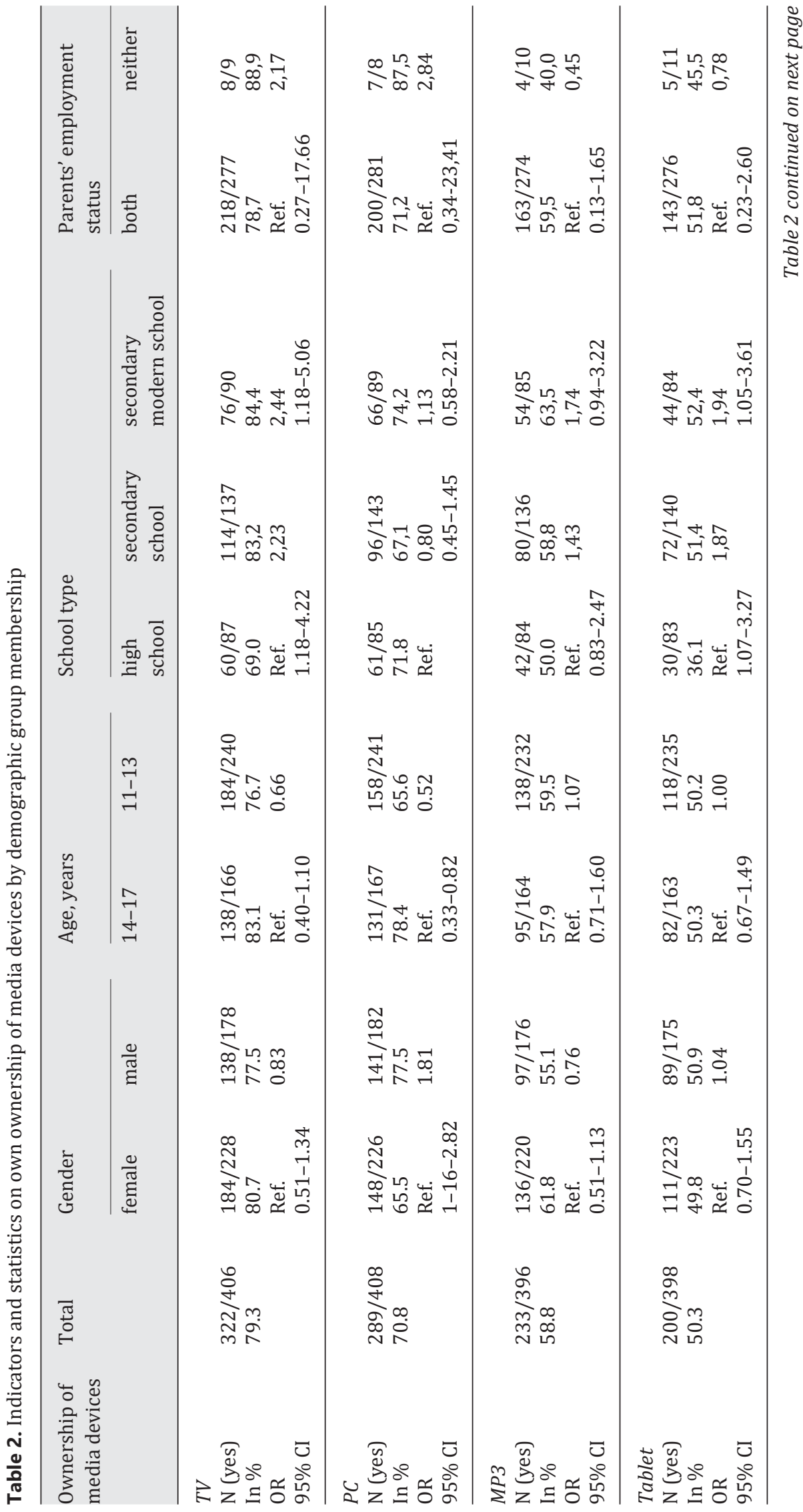




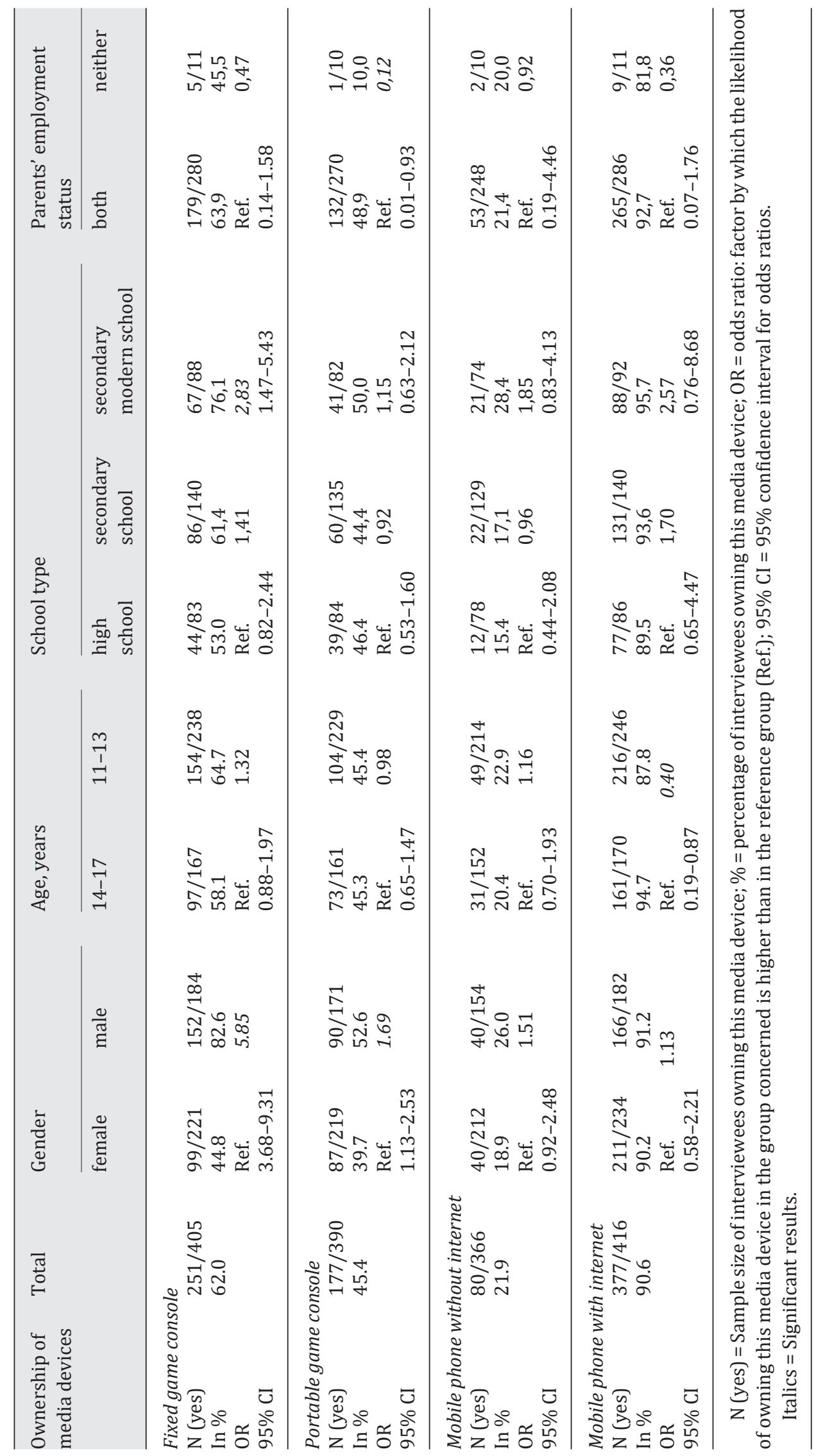


had their own TV. Compared to the reference group, pupils from secondary modern and secondary schools were more likely to have their own TV.

A computer was available in $96.6 \%$ of the households; $70.8 \%$ of the participants had their own PC. Age and gender differences were reported, with boys being more likely to have their own PC and a reduced likelihood to have their own PC among 11- to 13-year-olds compared to reference group.

MP3 players were available in 70.2\% of the households; $58.8 \%$ owned an MP3 player. The group comparison showed no socio-demographic differences.

Tablet PCs were accessible in $75.1 \%$ of the households; $50.3 \%$ of the participants had their own tablet. Students of secondary modern and secondary schools were more likely to own a tablet.

Game consoles were accessible in $80.0 \%$ of the households, whereby about two-thirds of the participants had their own permanent game console. Boys were more likely than girls and secondary modern school pupils more likely than high school students to own a game console.

Portable consoles were available in $56.4 \%$ of the households; $45.4 \%$ of the participants had their own portable console. Boys were reported to be more likely to own a portable console, and participants with unemployed parents were less likely to own a portable console.

In $42.3 \%$ of the households, mobile phones without internet access were available; $21.9 \%$ of the participants owned a mobile phone. The group comparison showed no socio-demographic differences between groups.

Mobile phones with internet access were available in $96.4 \%$ of households. $90.6 \%$ of the participants owned a mobile phone with internet access, while 11- to 13-year-olds were less likely to own a mobile phone compared to the reference group.

\section{Extent of Media Use}

The mean durations of daily media use (table 3 ) were reported to be $2.18 \pm 0.96 \mathrm{~h}$ for TV, $2.09 \pm 1.17 \mathrm{~h}$ for $\mathrm{PC}, 1.05 \pm 1.10 \mathrm{~h}$ for game consoles and $2.22 \pm 1.39 \mathrm{~h}$ for mobile phones (with and without internet access). The average overall media use was $7.54 \mathrm{~h} /$ day, with some media being used simultaneously.

Differences in TV use were found between school types. Pupils attending secondary modern schools spent on average more time watching TV than the reference group. Secondary modern school pupils watched most TV. $41.3 \%$ of them watched TV for at least $3 \mathrm{~h}$ daily.

Concerning the use of PCs, differences with regard to age and parents' employment status were revealed. 14- to 17-year-olds were using the PC more frequently than 11- to 13-yearolds. Children of unemployed parents spent on average more time using PC. Compared to the reference group, $34.2 \%$ of boys were found to be more likely to spent at least $3 \mathrm{~h} /$ day at the PC.

Analysing the use of game consoles, differences were revealed considering gender, age and type of school. Higher mean times of daily console use were registered in boys, 11- to 13 years-olds and pupils from secondary modern schools. Comparing console use and TV use (26.0\%), only $14.6 \%$ of the participants, in particular boys $(25.9 \%), 11$ - to 13 -year-olds $(17.5 \%)$ and pupils attending secondary modern schools $(27.2 \%)$, used game consoles for more than 3 h daily.

Age and gender differences were found in regard of mobile phone use. The highest mean daily mobile phone use was found in girls $(2.49 \mathrm{~h})$ and in 14- to 17-year-olds (2.57 h). Compared to the reference group, daily mobile phone use exceeding $3 \mathrm{~h}$ occurred more frequently among girls (64.1\%), 14- to 17-year-olds (64.3\%) and secondary modern school pupils $(64.1 \%)$. 
Wulff and Wagner: Media Use and Physical Activity Behaviour of Adolescent

Participants in Obesity Therapy: Impact Analysis of Selected Socio-Demographic

Factors

Table 3. Indicators and statistics on daily media consumption by demographic group membership

\begin{tabular}{|c|c|c|c|c|c|c|c|c|c|c|}
\hline \multirow[t]{2}{*}{$\begin{array}{l}\text { Daily media } \\
\text { consumption } \\
\text { (hours) }\end{array}$} & \multirow[t]{2}{*}{ Total } & \multicolumn{2}{|l|}{ Gender } & \multicolumn{2}{|c|}{ Age, years } & \multicolumn{3}{|c|}{ School type } & \multicolumn{2}{|c|}{$\begin{array}{l}\text { Parents' } \\
\text { employment } \\
\text { status }\end{array}$} \\
\hline & & female & male & $14-17$ & $11-13$ & $\begin{array}{l}\text { high } \\
\text { school }\end{array}$ & $\begin{array}{l}\text { secondary } \\
\text { school }\end{array}$ & $\begin{array}{l}\text { secondary } \\
\text { modern school }\end{array}$ & both & neither \\
\hline \multicolumn{11}{|l|}{$T V$} \\
\hline $\mathrm{N}$ & 507 & 276 & 231 & 250 & 257 & 107 & 206 & 45 & 328 & 27 \\
\hline MW & 2.18 & 2.16 & 2.20 & 2.20 & 2.16 & 2.07 & 2.13 & 2.33 & 2.17 & 2.26 \\
\hline SD & 0.96 & 0.95 & 0.96 & 0.98 & 0.93 & 0.91 & 0.87 & 1.13 & 0.89 & 1.02 \\
\hline MD & 2.00 & 2.00 & 2.00 & 2.00 & 2.00 & 2.00 & 2.00 & 2.00 & 2.00 & 2.00 \\
\hline IQA & 1.00 & 2.00 & 1.00 & 1.00 & 1.00 & 2.00 & 1.00 & 2.00 & 1.00 & 2.00 \\
\hline $\mathrm{Z}$ & & -0.540 & & -0.451 & & & -0.674 & -1.245 & -0.297 & \\
\hline $\mathrm{P}$ & & 0.589 & & 0.652 & & & 0.500 & 0.213 & 0.766 & \\
\hline \multicolumn{11}{|l|}{ Games console } \\
\hline $\mathrm{N}$ & 504 & 274 & 230 & 248 & 256 & 107 & 205 & 45 & 326 & 27 \\
\hline MW & 1.05 & 0.55 & 1.65 & 0.95 & 1.15 & 0.83 & 1.08 & 1.18 & 0.98 & 1.30 \\
\hline SD & 1.10 & 0.77 & 1.14 & 1.12 & 1.07 & 0.97 & 1.07 & 1.23 & 1.09 & 1.27 \\
\hline MD & 1.00 & 0.00 & 2.00 & 1.00 & 1.00 & 1.00 & 1.00 & 1.00 & 1.00 & 1.00 \\
\hline IQA & 2.00 & 1.00 & 1.00 & 2.00 & 2.00 & 1.00 & 2.00 & 2.00 & 2.00 & 2.00 \\
\hline $\mathrm{Z}$ & & -11.337 & & -2.684 & & & -2.061 & -1.490 & -1.263 & \\
\hline $\mathrm{p}$ & & $<0.001^{* *}$ & & $0.007^{* *}$ & & & $0.039^{*}$ & 0.136 & 0.206 & \\
\hline \multicolumn{11}{|l|}{$P C$} \\
\hline $\mathrm{N}$ & 505 & 275 & 230 & 249 & 256 & 107 & 204 & 45 & 326 & 27 \\
\hline MW & 2.09 & 2.00 & 2.19 & 2.35 & 1.84 & 2.16 & 2.09 & 2.20 & 2.12 & 1.63 \\
\hline SD & 1.17 & 1.17 & 1.17 & 1.12 & 1.16 & 1.13 & 1.15 & 1.31 & 1.17 & 1.39 \\
\hline MD & 2.00 & 2.00 & 2.00 & 2.00 & 2.00 & 2.00 & 2.00 & 2.00 & 2.00 & 1.00 \\
\hline IQA & 2.00 & 2.00 & 2.00 & & 2.00 & 2.00 & 2.00 & 2.00 & 2.00 & 2.00 \\
\hline $\mathrm{Z}$ & & -1.817 & & -5.041 & & & -0.568 & -0.369 & -2.130 & \\
\hline $\mathrm{p}$ & & 0.069 & & $<0.001^{*}$ & & & 0.570 & 0.712 & $0.033^{*}$ & \\
\hline \multicolumn{11}{|l|}{ Mobile phone } \\
\hline $\mathrm{N}$ & 506 & 277 & 229 & 249 & 257 & 107 & 205 & 45 & 327 & 27 \\
\hline MW & 2.22 & 2.49 & 1.90 & 2.57 & 1.89 & 2.14 & 2.20 & 2.33 & 2.25 & 2.15 \\
\hline $\mathrm{SD}$ & 1.39 & 1.37 & 1.34 & 1.39 & 1.16 & 1.39 & 1.40 & 1.38 & 1.37 & 1.33 \\
\hline MD & 2.00 & 2.00 & 2.00 & 3.00 & 2.00 & 2.00 & 2.00 & 2.00 & 2.00 & 2.00 \\
\hline IQA & 3.00 & 3.00 & 2.00 & 3.00 & 2.00 & 3.00 & 3.00 & 3.00 & 3.00 & 2.00 \\
\hline $\mathrm{Z}$ & & -4.844 & & -5.385 & & & -0.337 & -0.813 & -0.328 & \\
\hline $\mathrm{p}$ & & $<0.001^{* *}$ & & $<0.001^{* *}$ & & & 0.746 & 0.416 & 0.743 & \\
\hline
\end{tabular}

\section{Discussion}

To improve current obesity therapy approaches, intervention objectives need to be continuously adjusted depending on lifestyle and health problems. Moreover, to ensure a sustainable therapy success and outcomes, the content and methodological-didactical education strategies must be monitored and enhanced. New media offer further opportu- 
Wulff and Wagner: Media Use and Physical Activity Behaviour of Adolescent Participants in Obesity Therapy: Impact Analysis of Selected Socio-Demographic Factors

nities, which can be used to enhance the methodological repertoire and the flexibility (place and time) of obesity therapy. Media use and physical activity behaviour were analysed under consideration of socio-demographic factors to derive future intervention objectives, intervention measures as well as methodological obesity education strategies. These offer the potential to increase the effectiveness of existing obesity therapy approaches.

Limitations of this study should be emphasized before discussing the results. The generalisability of the results is limited by the selectivity of the present sample and the fact that media use is constantly changing. Future studies may consider sub-groups and characteristics of the sample, for instance weight and co-morbidities as well as the use of objective measurement tools.

The study results revealed that participants in obesity therapy do not exercise enough, as only $14.1 \%$ of the respondents metWHO physical activity recommendations [15]. Reference values of 11.5-14.8\% were found for the KIGGS national reference group [10]. In comparison to children from the KIGGS cohort [10], participants in obesity therapy were found to be similarly active. However, offers from sport clubs were used less frequently by them.

Regarding the classification of media access, the JIM study (youth information multimedia, baseline study for media use among 12- to 19-year-olds in Germany, $N=1,200$ ), carried out in the same year, should also be considered [16]: participants in obesity therapy were found to be more likely to own their own TVs (79\% vs. 57\%) as well as stationary games consoles (62\% vs. $50 \%)$ and to use media in higher volumes. Furthermore the mean daily duration of TV use in the JIM cohort [16] was 27 min shorter than among obesity therapy participants in this study.

The stratified analysis, which can be used to define intervention objectives, underlined that tailored therapy approaches are recommendable. For example, therapy approaches should focus on methods, which increase the activity of girls and 14- to 17-year-olds. Furthermore, participants of all socio-demographic groups were found to be more active with their friends and family. Girls, pupils at secondary modern school and children of unemployed parents were found to be far less likely to join a sports club. Hence, these groups should be encouraged to exercise regularly under professional supervision.

Regarding media access, digital media were commonly available and accessible in the households across all socio-demographic groups. Boys used game consoles more frequently, whereas 14- to 17-year-olds preferred mobile phones. The extent of media use exceeded the values of the reference groups in the KIGGS [10] and JIM cohort [16]. TVs, PCs and mobile phones were found to be used every day. In all socio-demographic groups, TVs and PCs were used to the same extent, while games consoles were especially used by boys. Furthermore, 14- to 17-year-olds tended to make considerable use of their mobile phones.

This results, which underline the high extent of media use and ownership, emphasise the importance of digital media for young people and for participants of obesity therapy in particular. This aspect is currently neglected and needs to be further considered in obesity therapy approaches and follow-up care as well as in handouts and manuals. Moreover, digital media could also be used to improve the organisational aspects of therapy.

Due to strongly varying extent of physical activity and media use between socio-demographic sub-groups, tailored therapy approaches and work in small groups with appropriate risk groups turn out to be highly relevant.

This implication is also supported by correlation analysis of media use and physical activity behaviour, which showed that socio-demographic factors affect the existence and extent of correlations. Despite the study's limitations, the results of this study are similar to other studies. Initial, cautious conclusions can be derived for content-related and methodological design of media-related intervention strategies, which should be screened in future studies. 
Wulff and Wagner: Media Use and Physical Activity Behaviour of Adolescent Participants in Obesity Therapy: Impact Analysis of Selected Socio-Demographic Factors

Two key findings should be emphasised: First, general behaviour patterns of all examined socio-demographic groups differed from the reference groups, and the outlined differences of exercise and media use between socio-demographic groups imply the need for tailored therapy approaches. Second, the general behavioural patterns of young obesity therapy participants, e.g. reduced levels of exercise, activity with family members and high use of TVs and PCs, should be addressed in therapy approaches.

Therapy approaches, which are socio-demographically differentiated, should address the low activity of girls and pupils from secondary modern schools and their lower involvement in club sports. Furthermore, parents and children should be supported with admission to sports clubs, e.g. support in finding appropriate sports clubs (activities) and assistance when applying for national subsidies, in particular for deprived families. Differentiated therapy approaches and effective methods, such as working in small groups, appears necessary as well, when attempting to modify obesity therapy and to consider the media habits of obesity therapy participants. Secondly, divergent behaviour patterns of media use were found between 11- to 13-year-olds and 14- to 17-year-olds. Attention of a media-related behavioural education could be put on excessive console use when addressing 11- to13-year-old boys and on mobile phone use when addressing 14- to 17-year-old girls. Apart from preventing excessive media use, physical activity during media use should be made a subject of discussion. This aspect should be further explored in future studies. Although there are many unanswered questions that have to be addressed in future research, the availability and use of digital media does not only pose health risks but also offers new ways of facilitating obesity therapy and follow-up care.

Future obesity therapy approaches need to consider media use in its procedures and content [17]. The results of this study show that PCs and mobile phones are particularly suitable due to availability and the many ways in which they can be used. Previous studies [18] suggested that appropriate media applications offer an efficient and user-friendly learning environment. The authors also recommend that particularly videos may become relevant for practice. Suitable examples are instructions for food preparation or training. Furthermore, apps for tablets or mobile phones could be used to monitor and document nutrition and physical activity. GPS and activity sensors can record activity and estimate data to energy intake. Social networks can be used to facilitate sharing of experience in groups, and video chat apps like Skype could be used for follow-up conversations.

However, there is still plenty of research to be done to finally understand which approaches to media use work best for each therapy setting and different patient groups. However, it appears also recommendable to encourage patients with high media use to use additional digital media if it can be justified. Furthermore, questions of how and when to integrate media into everyday therapy should be investigated. However, this raises further questions around data security, staff qualifications and also cost-benefit relations. Nonetheless, despite the well-known risks of digital media, they could proof to be beneficial to reach adolescents in their personal environment in order to improve their obesity therapy.

\section{Acknowledgement}

We would like to thank all participants, all obesity treatment centres as well as the 'Konsensgruppe Adipositasschulung für Kinder und Jugendliche e.V. (KgAS)' for their constructive and invaluable support. This research did not receive any grants from funding agencies in the public, commercial or not-for-profit sectors. 


\section{Disclosure Statement}

H. Wulff and P. Wagner declare that they have no conflict of interest.

\section{References}

1 Kurth B-M, Schaffrath Rosario A: Overweight and obesity in children and adolescents in Germany. Bundesgesundheitsbl Gesundheitsforsch Gesundheitsschutz 2010;53:643-652.

2 Guh DP, Zhang W, Bansback N, Amarsi Z, Birmingham CL, Anis AH: The incidence of co-morbidities related to obesity and overweight: a systematic review and meta-analysis. BMC Public Health 2009;9:88.

3 Konig H-H, Lehnert T, Riedel-Heller S, Konnopka A: Economic aspects of prevention and treatment of overweight and obesity in children and adolescents. Bundesgesundheitsbl Gesundheitsforsch Gesundheitsschutz 2011;54:611-620.

4 Arbeitsgemeinschaft Adipositas im Kindes- und Jugendalter (AGA): Konsensbasierte (S2) Leitlinie zur Diagnostik, Therapie und Prävention von Übergewicht und Adipositas im Kindes- und Jugendalter. www.aga. adipositas-gesellschaft.de/fileadmin/PDF/Leitlinien/AGA_S2_Leitlinie.pdf (last accessed July 20, 2018).

5 Kiess W, Sergejev E, Korner A, Hebebrand J: Is it possible to treat obesity in children and adolescents? Bundesgesundheitsbl Gesundheitsforsch Gesundheitsschutz 2011;54:527-532.

6 Hoffmeister U, Bullinger M, van Egmond-Frohlich A, Goldapp C, Mann R, RavensSieberer U et al: Evaluation of inpatient and outpatient care in Germany: the EvAKuJ study. Bundesgesundheitsbl Gesundheitsforsch Gesundheitsschutz 2011;54:128-135.

7 Oude Luttikhuis H, Baur L, Jansen H, Shrewsbury VA, O’Malley C, Stolk RP et al: Interventions for treating obesity in children. Cochrane Database Syst Rev 2009;1:CD001872.

8 Harris JL, Bargh JA: Television viewing and unhealthy diet: implications for children and media interventions. Health Commun 2009;24:660-673.

9 Plachta-Danielzik S, Landsberg B, Seiberl J, Gehrke MI, Gose M, Kehden B et al: Longitudinal data of the Kiel Obesity Prevention Study (KOPS). Bundesgesundheitsbl Gesundheitsforsch Gesundheitsschutz 2012;55:885891.

10 Manz K, Schlack R, Poethko-Muller C, Mensink G, Finger J, Lampert T: Physical activity and electronic media use in children and adolescents: results of the KiGGS study: first follow-up (KiGGS wave 1). Bundesgesundheitsbl Gesundheitsforsch Gesundheitsschutz 2014;57:840-848.

11 Lampert T, Sygusch R, Schlack R: Use of electronic media in adolescence. Results of the German Health Interview and Examination Survey for Children and Adolescents (KiGGS). Bundesgesundheitsbl Gesundheitsforsch Gesundheitsschutz 2007;50:643-652.

12 Suglia SF, Duarte CS, Chambers EC, Boynton-Jarrett R: Social and behavioral risk factors for obesity in early childhood. J Dev Behav Pediatr 2013;34:549-556.

13 Plachta-Danielzik S, Landsberg B, Lange D, Langnase K, Müller MJ: 15 years of the Kiel Obesity Prevention Study (KOPS). Results and its importance for obesity prevention in children and adolescents. Bundesgesundheitsbl Gesundheitsforsch Gesundheitsschutz 2011;54:304-312.

14 Opper E, Worth A, Wagner M, Bos K. The module 'Motorik' in the German Health Interview and Examination Survey for Children and Adolescents (KiGGS). Motor fitness and physical activity of children and young people. Bundesgesundheitsbl Gesundheitsforsch Gesundheitsschutz 2007;50:879-888.

15 World Health Organization: Global Recommendations on Physical Activity for Health. World Health Organization, Geneva, 2010.

16 Medienpädagogischer Forschungsbund Südwest (mpfs): JIM-Studie 2016. Jugend, Information, (Multi-) Media. Basisstudie zum Medienumgang 12- bis 19-Jähriger in Deutschland. Stuttgart, Medienpädagogischer Forschungsbund Südwest (mpfs), 2015. www.mpfs.de/fileadmin/files/Studien/JIM/2016/JIM_Studie_2016.pdf (last accessed July 20, 2018).

17 Reinehr T: Practical implementation of treatment guidelines concerning obesity in children and adolescents. Bundesgesundheitsbl Gesundheitsforsch Gesundheitsschutz 2011;54:591-597.

18 Shaw RJ, Bosworth HB, Silva SS, Lipkus IM, Davis LL, Sha RS, et al: Mobile health messages help sustain recent weight loss. Am J Med 2013;126:1002-1009. 